\title{
Development of a Budget Management Model for Managers in Public Hospitals in the Limpopo Province, South Africa
}

\author{
Nkhumeleni Mathobo ${ }^{1}$ \\ Mashupye Herbert Maserumule ${ }^{2}$ \\ Kabelo Boikutso Moeti ${ }^{3}$ \\ ${ }^{1,2, s}$ Tshwane University of Technology, Pretoria, South Africa \\ Email:mathobon@gmail.com Tel: (+27)152 936296/7 \\ Email:maserumulemh@tut.ac.za Tel:(+27)123 829 158/9255 \\ Email:moetikb@tut.ac.za Tel:(+27)123829552
}

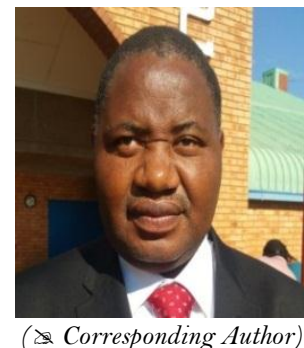

\begin{abstract}
Budget management remains a challenge in public hospitals with regard to the delivery of cost effective health services. This article is based on a study undertaken to develop a budget management model for managers in public hospitals in the Limpopo Province of South Africa. The question is: How can the management of the budget in public hospitals be improved? The study investigates budget management in the public hospitals. The research methodology used for this study is both quantitative and qualitative research design to generate data required to achieve its aim and objectives. The targeted population for the study was all public hospitals in the Limpopo Province, which comprises 40 public hospitals. The findings showed that, as there is improvement in budget management, much needs to be done to improve budget management in the public hospitals. In this study a budget management model is recommended for consideration by managers.
\end{abstract}

Keywords: Budget planning, Budget control.

Citation | Nkhumeleni Mathobo; Mashupye Herbert Maserumule; Kabelo Boikutso Moeti (2018). Development of a Budget Management Model for Managers in Public Hospitals in the Mrovince, and ent Studies, 5(3): 87-90.

History:

Received: 12 February 2018

Revised: 18 May 2018

Accepted: 21 May 2018

Published: 23 May 2018

Licensed: This work is licensed under a Creative Commons

Attribution 3.0 License (oc)

Publisher:Asian Online Journal Publishing Group
Contribution/Acknowledgement: All authors contributed to the conception and design of the study.

Funding: This study received no specific financial support

Competing Interests: The authors declare that they have no conflict of interests.

Transparency: The authors confirm that the manuscript is an honest, accurate, and transparent account of the study was reported; that no vital features of the study have been omitted; and that any discrepancies from the study as planned have been explained.

Ethical: This study follows all ethical practices during writing.

\section{Contents}

1. Introduction

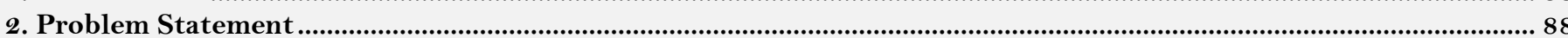

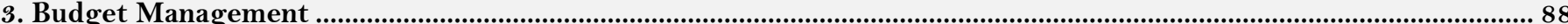

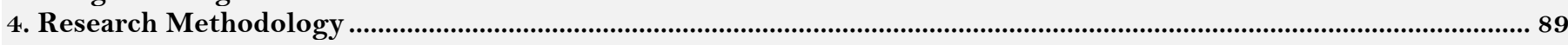

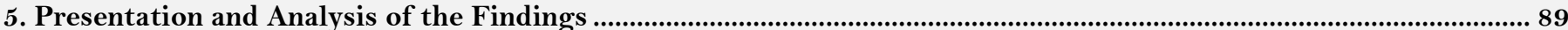

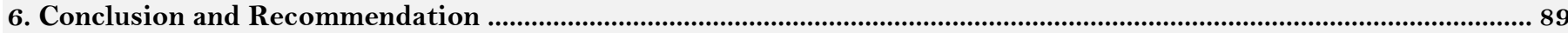

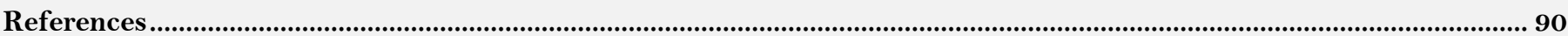




\section{Introduction}

Limpopo Province is approximately $80 \%$ rural based, the majority of people depend on public hospitals for health services. This is also due to the high level of unemployment and poverty. The focus of this study is on budget management in public hospitals in the Limpopo Province. According to Moeti et al. (2007) managing a budget covers budget preparations, budget implementations, and budget control. There is a need for effective budget management in public hospitals to improve service delivery. In this study, the development of a budget management model for managers in public hospitals in the Limpopo Province to improve budget management is explored. The Limpopo Province has 40 hospitals divided into district hospitals, regional hospitals, specialized hospitals, as well as tertiary hospitals. Budget management in these hospitals is a challenge. A budget is a financial statement which contains the estimates of revenue and budget over a certain period of time (Gildenhuys, 1993). A budget is a policy statement declaring the goals and specific objectives an authority wishes to achieve by means of expenditure concerned and it is a public policy expressed in amounts of money (Gildenhuys, 1993). Lynch 1979 (in (Schwella et al., 1996)) defines budget as "a plan for achieving programs related to goals and objectives within a definite time, incorporating estimates of resources required, together with estimates of resource available, usually compared with one or past periods and showing future requirements". A budget is a plan which is seen as a crucial input in the delivery of health services by public hospital.

\section{Problem Statement}

The management of budget is a challenge for managers in public hospitals. The extent of such a challenge ranges from limited knowledge of legislative requirements for budget management, budget preparation and budget implementation to budget control. There is no budget management model or tool that can be used as guide and manual for budget planning, budget implementation, and budget control in the public hospitals. The result of this is ineffective budget management.

\section{Budget Management}

Budget management remains a challenge in public hospitals. This hampers effective delivery of cost effective health services. There is a need for effective budget management in public hospitals to improve service delivery. Budget management process consists of three phases, namely, budget planning, implementation and control. Budget management phases are discussed below in full:

\subsection{Budget Planning}

Budget planning is the integral part of the strategic planning. Budget planning process starts with strategic planning. Strategic planning is defined as "a management process that combines four basic features: (1) the clear statement of the organisation's mission; (2) the identification of the department's external constituencies or stakeholders, which determine the assessment of the department's purpose and operations; (3) the delineation of the department's strategic goals and objectives, typically a 3 to 5 year plan; and (4) the development of strategies to achieve them (Berry, 1994). Strategic planning can be described as a map to achieve an organization's objectives. The vision, strategic objectives and target must be achieved through this map. The purpose of strategic planning is to operationalize the strategies developed through strategic thinking and support strategic thinking process (Heracleous, 1998) Strategic planning is an important element in the management of public hospitals which ought to happen every year. Failure to plan may result in a department or public hospital unable to achieve its objectives. The strategic planning and budget planning should be combined for the budget to be effective. The budget planning process should be linked with the budget planning process. The vision, mission, strategic objectives, activities, performance indicators must be developed with clear targets. These activities must be costed. Then the budget is prepared based on the costing service and inputs from strategic planning.

\subsection{Budget Implementation}

Budget implementation refers to the spending of budget. The Republic of South Africa (1996) (Act 108 of 1996), chapter 10, section 195 requires managers to promote efficient, economic, and effective use of resources. The RSA (1999) section 38 (1) (b) states that "the accounting officer of the department, trading entity or constitutional institution is responsible for effective, efficient, economic and transparent use of resources". The heads of sections within the public hospital are responsible for budget implementation or spending. The performance of budget management is measured in terms efficiency, effectiveness, and economy. According to Kloot (1999) efficient is defined as "maximizing output for a given set of required inputs, or minimizing inputs for output, economy is defined as acquiring resources in appropriate quantity and at least cost, and effective is the extent to which a defined task has been accomplished". According to Mayne and Zapico-Goñi (1997) "the best known performance measure are the traditional ' 3 Es': economy (minimizing the consumption of inputs), efficiency (the relationship between inputs and outputs), and effectiveness (outcomes achieved as compared to expectations)". The public hospitals should be able to use minimum resources in the delivery of quality health services. The budget must be managed in a way that the strategic objectives and targets set in the annual performance plan of the public hospital are achieved. The procurement of goods and services should be at the lowest price within the essential given quality and quantity to achieve value for money.

\subsection{Budget Control}

According to Khan and Jain (2007) "budgeting control and periodic comparisons between budget and actual expenditure would reveal relative budgeting efficiency". Banerjee (2006) points out that the following steps are involved in budgeting control:

- Establishment of targets;

- Measurements of actual expenditure;

- Comparison of actual expenditure with budgeted targets to determine deviations or variances; and 
- Analysis of the causes of variations and reporting.

According to Public Financial Management Act (Act 1 of 1999 as amended by act 29 of 1999) chapter 5 section 39 states that "the Accounting Officer of a department is responsible for ensuring that, effective and appropriate steps are taken to prevent unauthorized expenditure". The Accounting Officer, for the purpose of subsection (1) must "take effective appropriate steps to prevent any overspending of the vote of the department and the main division within the vote". Budget control is an important tool to monitor and control budget, without budget controls public hospital will overspend the budget. The over-expenditure of allocated budget is categorized as unauthorized expenditure. The unauthorized expenditure is not permitted in terms of PFMA. Therefore it is the responsibility of managers to ensure that public hospital remains within budget allocation. The budget is also used as a tool to prevent over/under expenditure of budget allocation.

\section{Research Methodology}

The research approach for this study is both quantitative and qualitative research design. Quantitative research is based on measuring variables for individual participants to obtain scores, usually numerical values, which are submitted to a statistical analysis for summary and interpretation (Gravetter and Forzano, 2009). Quantitative research is basically answering research questions using numbers (statistics). The researcher collects numerical data and analyzed it statistically. Qualitative research is an approach for exploring and understanding the meaning individuals or groups ascribe to a social or human problem. This process of research involves emerging questions and procedures, data typically collected in the participant's setting, and the researcher interpretation of the meaning of data (Creswell, 2014).

The targeted population for the study was all public hospitals in the Limpopo Province, which comprises 40 public hospitals. The sample size of 20 public hospitals was drawn from the population of 40 public hospitals, which represented 50\%. Therefore, 120 managers participated in the study: [20 public hospitals X 6 managers per public hospital]. A questionnaire was used as the primary data-gathering instrument. The study was also piloted. Data was quantitatively and quantitatively analyzed. The quantitative analysis used STATA V13 statistical software. The results of the Cronbach alpha test to confirm reliability of the data showed a high internal consistency. The qualitative analysis used analytical and interpretive techniques to generate descriptive data required to answer the research question. The results of both qualitative and quantitative analyses were triangulated and aggregated into a coherent whole to authenticate the validity of the findings / conclusions of the study.

\section{Presentation and Analysis of the Findings}

\subsection{Budget Planning}

A budget is a plan which is seen as a crucial input in the delivery of health services by public hospitals. A budget is a business plan expressed in terms of monetary value. The respondents were asked to assess budget planning in the public hospitals. The findings showed that, as there was little improvement in budget planning, much needs to be done. For budget planning remain a management challenge most managers of public hospitals.

\subsection{Budget Implementation}

The managers are responsible for budget implementation in public hospitals. The delivery of effective service delivery depends largely on the effective implementation of budget. The respondents were asked to assess budget implementation in the public hospitals. The findings showed that, as there was little improvement in budget implementation, much needs to be done. For budget implementation remain a management challenge most managers of public hospitals.

\subsection{Budget Control}

Budget control is an important tool to monitor and control budget. Without budget controls public hospitals will overspend the budget. The respondents were asked to assess budget controls in the public hospitals. The findings revealed that, as there was little improvement in budget control, much needs to be done. For budget control remain a management challenge most managers of public hospitals. It can be concluded that budget management remain a management challenge for most managers of public hospitals in the Limpopo Province.

\section{Conclusion and Recommendation}

This article undertook to develop a budget management model for managers in public hospitals in the Limpopo province. The study concluded that budget management remains a management challenge for most managers of public hospitals in the Limpopo Province. The study recommended the budget management model for managers in public hospitals. The Figure 1.1 below is the budget management model. 


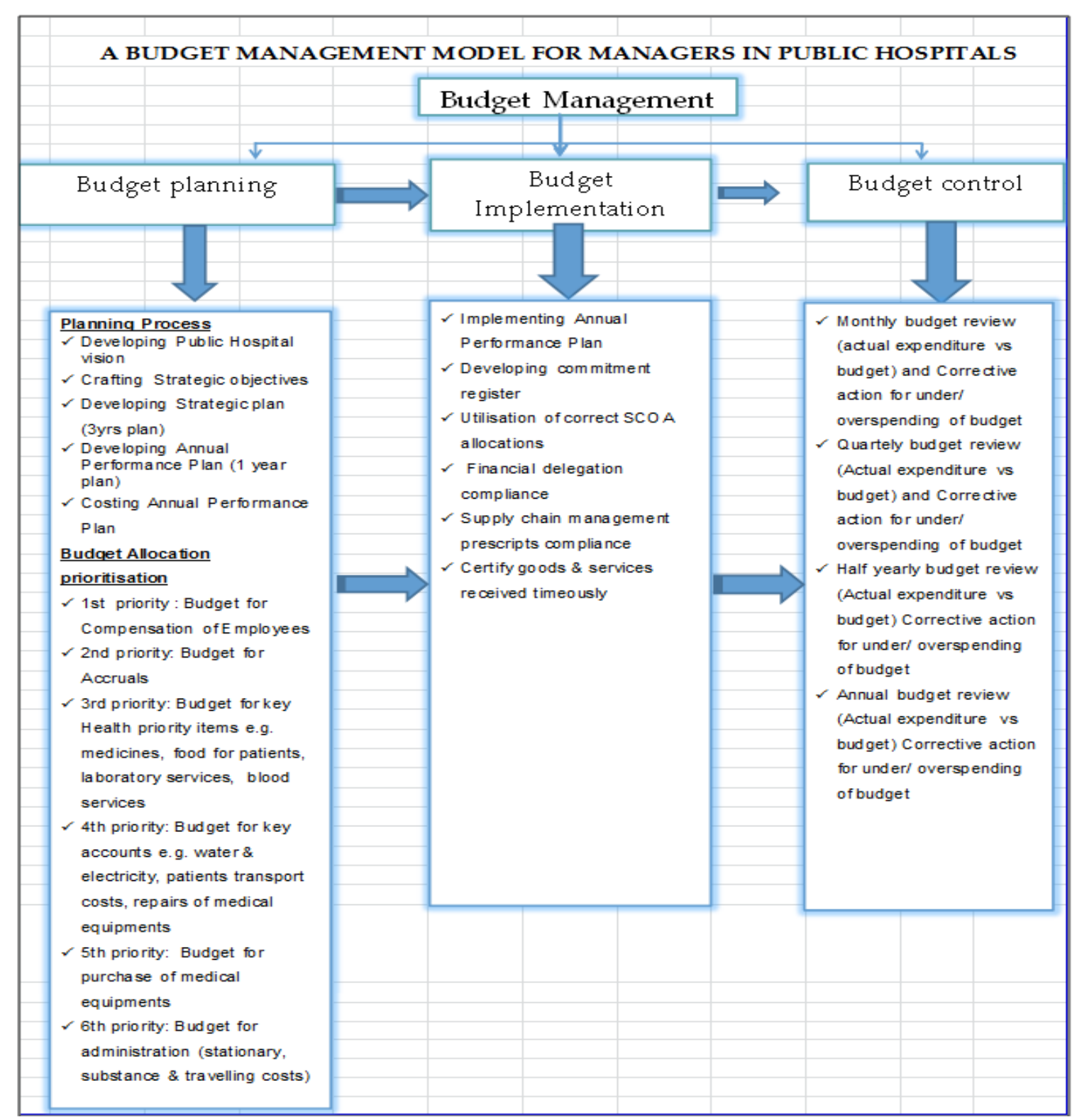

Figure-1.1. A budget management model for mangers in public hospitals

The model was designed to improve budget management. It covers budget planning, budget implementation, and budget control. The delivery of cost effective health services in the public hospitals depends on an effective budget management model for managers.

\section{References}

Banerjee, B., 2006. Cost accounting: Theory and practice. 12th Edn., New Delhi: Prentice Hall.

Berry, F.S., 1994. Innovation in public management: The adoption of strategic planning. Public Administration Review, 54(4): 322-330. View at Google Scholar | View at Publisher

Creswell, J.W., 2014. Research design qualitative, quantitative and mixed methods approaches. 4th Edn., Los Angeles: Sage Publications, Inc.

Gildenhuys, J.S.H., 1993. Public financial management. 1st Edn., Pretoria: Van Schaik Publishers.

Gravetter, F.J. and L.B. Forzano, 2009. Research methods for the behavioural sciences. 3rd Edn., Belmont: Wadsworth.

Heracleous, L., 1998. Strategic thinking or strategic planning. Long Range Planning, 31(3): 481- 487. View at Google Scholar View at Publisher

Khan, M.Y. and P.K. Jain, 2007. Management accounting. 4th Edn., New York: MacGraw- Hill.

Kloot, L., 1999. Performance measurement and accountability: Victorian local government. International Journal of Public Sector Management, 12(7): 565-583. View at Google Scholar View at Publisher

Mayne, J. and E. Zapico-Goñi, 1997. Monitoring performance in the public sector: Future direction from international experience. New Jersey: Transaction Publishers.

Moeti, K., T. Khalo, J. Mafunisa, S. Nsingo and T. Makondo, 2007. Public finance fundamentals. Cape Town: Juta.

Republic of South Africa, 1996. Constitution of the Republic of South Africa, 1996. Pretoria: Government Printers.

RSA, 1999. Public finance management act (act 1 of 1999 as amended by act 29 of 1999). Pretoria: Government Printers.

Schwella, E., J. Burger, W. Fox and J.J. Muller, 1996. Public resource management. 1 st Edn., Cape Town: Juta. 